\title{
Light Removes Inactivation of the A-Type Potassium Channels in Scallop Hyperpolarizing Photoreceptors
}

\author{
Yuichi Shimatani and Yasuo Katagiri \\ Department of Physiology, Tokyo Women's Medical College, Shinjuku-ku, Tokyo 162, Japan
}

\begin{abstract}
The properties of light-activated and voltage dependent conductances in the hyperpolarizing photoreceptors of the isolated retina of the giant scallop (Patinopecten yessoensis) have been studied in whole-cell voltage-clamp recordings. Resting membrane potential of the cells was -35 to $-60 \mathrm{mV}$ in the dark. Large outward current was maintained during illumination when the cell was voltage clamped at the resting potential. Previous reports have shown that the hyperpolarizing response to light and the light-activated outward current are mediated by an increase of a conductance of $\mathrm{K}^{+}$channels in the plasma membrane (Gorman and McReynolds, 1974; Gomez and Nasi, 1994a). This report shows that the light-activated $\mathrm{K}^{+}$channels of this photoreceptor cell generate the voltage-dependent transient outward current in response to depolarizing voltage steps in the dark. The characteristic of this current resembles the typical voltage-dependent transient current (A-current) of molluscan neurons in the kinetics of activation and inactivation, and in the blockage by 4-aminopyridine (4-AP). However, the voltage-dependent transient current during illumination becomes a flat stable form which inactivation process disappeared. We report here that light removes inactivation of the $\mathrm{K}^{+}$channels which generate the voltagedependent transient outward currents in the dark.
\end{abstract}

[Key words: scallop eye, hyperpolarizing photoreceptor, potassium channel, inactivation, A-current, light-activated channel]

Receptor potential in photoreceptors appears as a result of change in membrane conductance via intracellular transmitter after absorption of light by photopigment rhodopsin. In invertebrates, most photoreceptors bear microvilli as photoreceptive membranes and respond to light with depolarizing receptor potential by increasing the membrane conductance of cation permeable channels (Clark et al., 1969; Millecchia and Mauro, 1969; Brown and Blinks, 1974; Hardie, 1991b). In contrast, hyperpolarizing photoreceptors of invertebrates are found in mollusc. This type of photoreceptor is formed by modified cilia instead of microvilli (Barber et al., 1967; Gorman and McReynolds, 1969; Mpitsos, 1973; Wilkens, 1984; Katagiri et al., 1985).

Vertebrate photoreceptors hyperpolarize in response to light

\footnotetext{
Received Jan. 17, 1995; revised June 1, 1995; accepted June 5, 1995.

We express our gratitude to Professor Yoko Hashimoto, not only for her criticism, but also for her interest and encouragement.

Correspondence should be addressed to Yuichi Shimatani, Department of Physiology, Tokyo Women's Medical College, 8-1 Kawadacho, Shinjuku-ku, Tokyo 162, Japan.

Copyright @ 1995 Society for Neuroscience $0270-6474 / 95 / 156489-09 \$ 05.00 / 0$
}

by closing the cGMP-gated cation channels on the plasma membrane (Fesenko et al., 1985). On the other hand, the hyperpolarizing receptor potential of Pecten ciliary-type photoreceptor cells is caused by an increase of $\mathrm{K}^{+}$conductance (Gorman and McReynolds, 1974, 1978). Electrophysiological studies by intracellular recordings from Pecten have shown that the ciliary-type photoreceptor is different from microvilli-type in several respects which may reflect differences in the phototransduction mechanisms (McReynolds and Gorman, 1970a,b; McReynolds, 1976). However, the technical difficulty of performing a stable recording from the small photoreceptors has retarded research of the mechanisms of phototransduction in the ciliary-type cells.

Recently, it has been possible to perform single-channel or whole-cell patch-clamp recordings from the enzymatically isolated ciliary-type photoreceptors of Pecten and Lima (Gomez and Nasi, 1994a, 1994b) or from the visually identified photoreceptors on the nonenzymatically treated retinal tissues of $\mathrm{Pa}$ tinopecten. These studies reconfirmed that light causes an increase of a conductance of $\mathrm{K}^{+}$channels, and revealed several features of light-activated channels that were not reported in the earlier studies. Interestingly, the light-induced currents of these species show remarkable voltage dependency and are strongly blocked by 4-AP, a classical blocker of A-lype $\mathrm{K}^{+}$channels (Gomez and Nasi, 1994a,b).

In this study, we describe the unique characteristics of Patinopecten light-activated $\mathrm{K}^{+}$channels. In both photoreceptors of vertebrates and invertebrates, the known photosensitive channels are not activated or inactivated by voltage alone. In contrast, the light-activated $\mathrm{K}^{+}$channels show a transient activation and inactivation in response to a depolarizing voltage step even in the absence of light. The kinetics of the transient $\mathrm{K}^{+}$current in the dark is similar to A-current in molluscan neurons. Our results suggest that the hyperpolarizing receptor potential of Patinopecten ciliary-type photoreceptor is generated by removing inactivation of $\mathrm{K}^{+}$channels.

\section{Materials and Methods}

Preparation. The experiments were performed on the isolated retina of the mantle eye of a giant scallop, Patinopecten yessoersis. Specimens were obtained from the scallop-farm in Aomori Prefecture, Japan, and kept in artificial sea water (ASW) at $11^{\circ} \mathrm{C}$ for several weeks under natural light-dark cycle before experiments. The sea water was filtered and aerated continuously.

Patinopecten yessoensis has $60-90$ eyes $500-900 \mu \mathrm{m}$ in diameter arranged around the mantle. Individual eyes were removed from the mantle and dissected under the binocular dissection microscope with dim red light illumination $(\lambda>600 \mathrm{~nm})$. The pigment epithelium, cornea, lens, and argentea were removed to expose the retina. Both optic nerves of the distal and proximal retina were cut off near their basal parts. The basement membrane, which covered the distal surface of the retina, was scratched out roughly with fine glass needles to expose the 
ciliary-type photoreceptor cells. As a result of this operation, photoreceptors located on the top surface of the retina were easily identified by their diameter $(10-15 \mu \mathrm{m})$ and spherical shape in the view of the microscope. No enzyme treatment was used during the dissection procedure.

The isolated retina was placed with the distal face upward, in a perfusion chamber on the stage of an inverted microscope (Nikon, TSM, Tokyo, Japan). Oxygenated solutions were perfused continuously by the peristaltic pump at a rate of $2 \mathrm{ml} / \mathrm{min}$, and were cooled to $11^{\circ} \mathrm{C}$ by a bath temperature controller (Dia Medical System, Tokyo, Japan) just before entering the chamber.

Electrophysiological recordings. A whole-cell patch clamp technique according to Hamil et al. (1981) was applied to the ciliary-type photoreceptors on the distal surface of isolated retina. Patch pipettes were fabricated from fiber-filled borosilicate glass capillaries (A-M Systems, \#6035) with a vertical puller (Narishige, PP-83, Tokyo, Japan) whose $\mathrm{AC}$ power supply was modified for improvement of accuracy to a regulated DC power supply. The pipettes were fire polished with resistance of $5-10 \mathrm{M} \Omega$ just before use. The tip of the pipettes were attached to the exposed membrane of the identified photoreceptor under dim red light illumination $(\lambda>600 \mathrm{~nm})$.

Membrane currents were recorded with a patch-clamp amplifier (List Electronic, EPC-7). Liquid-junction potentials (4 mV) were nulled just prior to seal formation and corrected as described by Fenwick at al. (1982).

The whole-cell configuration was achieved by rupture of the cell membrane with suction. Series resistance measured from the amplitude of the capacitive transients was 10-20 M $\Omega$ and was corrected, if necessary, with series resistance compensation circuit of the patch-clamp amplifier. After the formation of conventional whole-cell conditions, the red dim illumination of the microscope was turned off. So, the "dark" means the completely dark conditions in all experiments. Signals were stored on a DAT recorder (SONY, PC-108M, Tokyo, Japan) and digitized on line by a 12 bit, DA converter (National Instruments, MIO-16 multifunction I/O board) with a sampling interval of 25-100 $\mu \mathrm{sec}$. Data were acquired and analyzed by original software on an Apple Macintosh II computer.

Light stimulation. Green monochromatic light from high intensity LED (Stanley, HPG5066X, Tokyo, Japan, $\lambda$ peak $=560 \mathrm{~nm}$ ) was used. The unattenuated light intensity measured at the level of the retina was $200 \mu \mathrm{W} / \mathrm{cm}^{2}$ and evoked saturated responses in the ciliary-type photoreceptor cells. Intensity of light stimuli was expressed in log units relative to this value and was controlled, via a voltage-current converter circuit, by the command wave forms generated using Macintosh II computer.

Solutions. ASW had the following composition: $425 \mathrm{~mm} \mathrm{NaCl}, 9 \mathrm{~mm}$ $\mathrm{KCl}, 9 \mathrm{~mm} \mathrm{CaCl}, 49 \mathrm{~mm} \mathrm{MgCl} 2,10 \mathrm{~mm}$ IILPES (plI was titrated to 7.8 at $11^{\circ} \mathrm{C}$ with $\mathrm{NaOH}$ ). The nominally $\mathrm{Ca}^{2+}$-free solution (0 Ca ASW) was made by exchanging $\mathrm{Ca}^{2+}$ for $\mathrm{Mg}^{2+}$ on an equimolar basis.

The pipette solution contained $310 \mathrm{mM} \mathrm{K}$-aspartate, $50 \mathrm{mM} \mathrm{KCl}, 10$ $\mathrm{mM} \mathrm{NaCl}, 2 \mathrm{mM} \mathrm{MgCl}$, $1.5 \mathrm{~mm}$ EGTA, $270 \mathrm{~mm}$ sucrose, and $10 \mathrm{~mm}$ HEPES buffered to $\mathrm{pH} 7.4$ with $\mathrm{KOH}$ (free $\mathrm{Ca}^{2+}$ concentration $2 \times$ $10^{-7} \mathrm{M}$ ). Tetraethyl-ammonium chloride (TEA) and 4-aminopyridine (4AP) were obtained from Sigma Chemical Co. Drugs were dissolved in the bath solution just before each experiment.

\section{Results}

Using the whole-cell configuration of the patch-clamp technique, it was possible to obtain tight, cell attached seals $(>10 \mathrm{G} \Omega)$ and subsequently whole-cell recordings from nonenzymatically treated ciliary-type photoreceptors. We found no distinct variation in the response of photoreceptors, though about $15 \%$ of cells showed no response or only the slight response to light and were not used. The light response was stable for more than $20 \mathrm{~min}$ in most cells. Although it was possible to record from photoreceptors for an hour, such long recordings usually caused an unpreventable decline of the light response.

\section{Light-activated $K^{+}$currents in ciliary-type photoreceptors}

The resting potentials of photoreceptors were relatively low (mean $\pm \mathrm{SD},-45 \pm 12 \mathrm{mV} ; n=48$ ) in the dark. This value is considered to be normal for ciliary-type photoreceptors in bivalvia as has been reported by others (McReynolds and Gorman, 1970a; Gomez and Nasi, 1994a).

A light stimulus activated the outward current in the photoreceptors (Fig. 1). Previous studies revealed that the light-activated outward current is a $\mathrm{K}^{+}$current generated by an increase of $\mathrm{K}^{+}$conductance (Gorman and McReynolds, 1978; Gomez and Nasi, 1994a).

The amplitudes of the saturating responses produced by bright light stimuli were $200 \mathrm{pA}$ to $1 \mathrm{nA}$ when the cells were voltage clamped at their resting potential levels (Fig. $1 A, B$ ). As has been reported by others, the ciliary-type photoreceptors of scallop do not show the rapid adaptation to repeated light stimuli that is general in microvilli-type photoreceptors (McReynolds, 1976). In most experiments, the duration of light stimuli was 2-3 sec and the interval of stimuli was $1 \mathrm{~min}$ or more. Under these conditions, the light-activated current reached its peak within 1.5 sec and decayed very slowly in the continuous light stimulation, and they showed no distinct adaptation to the repeat of light stimulation (see Fig. 1D).

Time course of the light-activated current was affected by bath temperature. Rising and falling rate of the response may be relatively slow with our low experiment temperature $\left(11^{\circ} \mathrm{C}\right)$ in comparison with other preparations (McReynolds and Gorman, 1970a; Gomez and Nasi, 1994a). These rates were accelerated accordingly as bath temperature increased (data not shown).

Activation of the light-activated current was clearly voltage dependent in ASW (Fig. 1B,C). The light-activated conductances $(G)$ were calculated from the amplitude of light-activated current $(I)$ measured at each holding potential $(V)$, using the relation

$$
G=I /(E-V),
$$

where $E$ is the reversal potential of light-activated current measured from the tail currents elicited by applying voltage steps at the peak of currents $(-86 \pm 4 \mathrm{mV}, n=3)$. This value was almost exactly the Nernst $\mathrm{K}^{+}$equilibrium potential $(-91 \mathrm{mV}$ at $11^{\circ} \mathrm{C}$ ), and close to the reversal potential of Pecten or Lima ( $\approx-80 \mathrm{mV}$ ) estimated by others (Gomez and Nasi, 1994a).

The relation between the conductances and the voltages was fit to the Boltzmann equation of the form

$$
G / G_{\max }=1 /\left\{1+\exp \left[\left(V-V_{1 / 2}\right) / k\right]\right\},
$$

where $G_{\max }$ is the maximum conductance, $V_{1 / 2}$ is the voltage at which half the conductance is activated and $k$ is a slope factor of the curve. The light-activated conductance is reduced at voltages more negative than $-20 \mathrm{mV}$ (Fig. $1 C$ ). $V_{1 / 2}$ value determined by curve fitting was $-57 \pm 5 \mathrm{mV}(n=5)$ and significantly more negative than the resting potentials in the dark $(0.02$ $<P<0.05$, using a two-tailed $t$ test). Additionally, the lightactivated current did not reverse in ASW even if the membrane voltage was clamped more negatively than the $\mathrm{K}^{+}$equilibrium potential, because light did not activate any conductance at such a voltage level (Fig. $1 B$ ).

As has been reported in some species (Gomez and Nasi, 1994b), 4-AP blocks the light-activated $\mathrm{K}^{+}$currents of ciliary-type photoreceptors. External application of 4-AP substantially reduced light-activated currents in submillimolar order. The light-activated current was almost completely blocked by $2 \mathrm{mM} 4-\mathrm{AP}$ ( $>97 \%$ of the peak current, $n=5$ ) as shown in Figure $1 D$. The blockage by 4 -AP was reversible, but in millimolar concentrations, only part of the response was recovered up to the end of recording. Usually, the 4-AP 
A

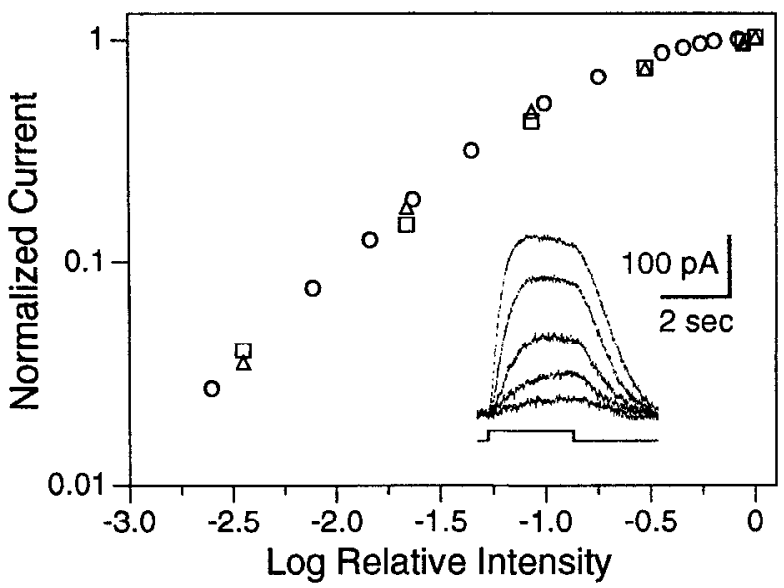

C

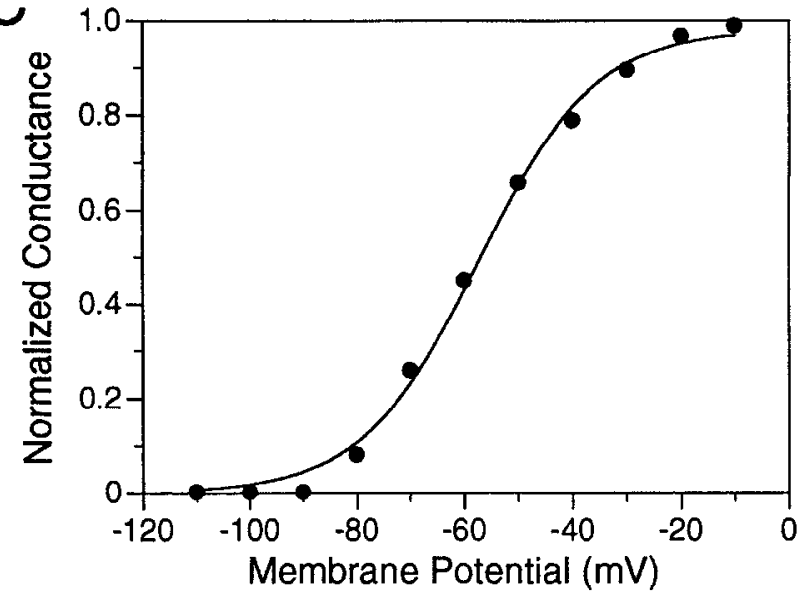

B

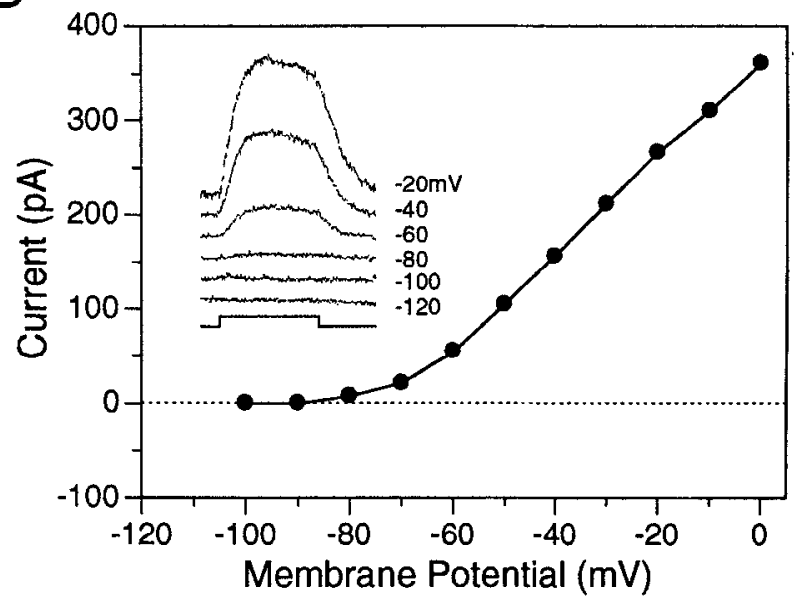

D

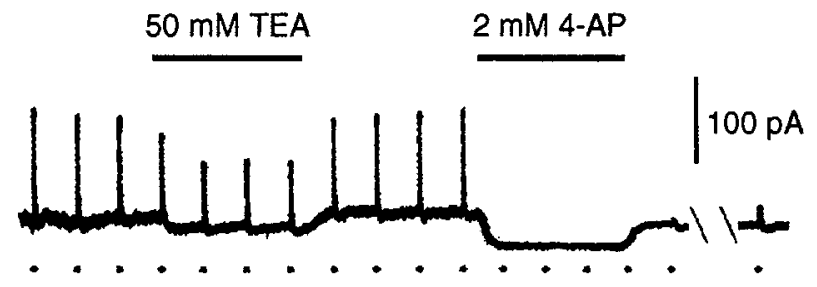

Figure 1. The light-activated $\mathrm{K}^{+}$currents in the ciliary-type photoreceptors of Patinopecten yessoensis. A, Response-intensity relation of the lightactivated currents for three cells from the same retina. Peak amplitudes of the responses to 2.5 sec steps of light are normalized to the values obtained with unattenuated light intensity $(\log I=0)$ and plotted logarithmically against the $\log$ relative intensity of light. The inset shows an example of the responses to light of increasing intensity ( $\log I=-2.0,-1.5,-1.0,-0.5$, and 0 ). The cells were voltage clamped at $-40 \mathrm{mV}$. $B$, Voltage dependence of the light-activated currents. Voltage-cument relation is plotted for the peak anplitudes of the light-activated currents elicited by $3 \mathrm{sec}$ step of light $(\log I=-0.5)$. Data from one cell. Light step was applied $2 \mathrm{sec}$ after the voltage step from the resting potential to each holding potential. The inset shows families of response at holding potentials from -120 to $-20 \mathrm{mV}$ in $20 \mathrm{mV}$ steps. Scale of the inset is the same as in $A$. $C$, Voltage-conductance curve from the same data in $B$. Light-activated conductance were calculated and normalized by the method described in Results. The curve fitted to the data is the Boltzmann function where slope -10.8 and $V_{12}-57.3$. Interval of data acquisition is 1 min $(A-C)$. D, Effects of TEA and 4-AP on responses to $2 \mathrm{sec}$ steps of light. The cell was voltage clamped at $-40 \mathrm{mV}$. The time interval between steps of light is $1 \mathrm{~min} ; 50 \mathrm{~mm}$ TEA was added to the bath solution (ASW) without changing other constituents. After the light-activated currents recovered completely by removing TEA, $2 \mathrm{~mm} 4$-AP was added to the bath. The separation indicates the time interval of $13 \mathrm{~min}$.

of this concentration slightly shifted the dark level of the membrane current in the inward direction. We also tested the effect of TEA. TEA also reduced the light-activated currents but less effectively than 4-AP (Fig. 1D). High concentration of TEA in external solution (up to $50 \mathrm{~mm}$ ) decreased only $30-40 \%$ of the light-activated current $(n=3)$. The effects of TEA almost completely recovered by removing it from the bath solution.

\section{Voltage-activated $\mathrm{K}^{+}$currents in the dark}

In the dark, depolarizing voltage steps from hyperpolarizing holding potential activated prominent outward currents as shown in Figure 2A. The macroscopic currents were separated into at least two classes of voltage-activated $\mathrm{K}^{+}$currents by their voltage dependency or pharmacological properties. The fast inactivating transient current was activated when depolarizing steps up to $-30 \mathrm{mV}$ were applied from holding potentials more negative than $-70 \mathrm{mV}$ (Fig. $2 \mathrm{~B}$ ). The transient current rose rapidly to a peak and then inactivated exponentially. The slower maintained current was activated at more depolarized levels. When depolarizing steps were applied from the holding potential of $-50 \mathrm{mV}$, at which transient current inactivated completely, to more positive than $-30 \mathrm{mV}$, only the maintained current was activated (Fig. $2 C$ ). The maintained current also showed inactivation, but it was very slow with a time constant of 1-2 sec, and was only a part of activated current $(30-40 \%, n=5)$. The reversal potentials were estimated by the tail currents elicited with step repolarizations to different voltages applied at the peak or the maintained phase of total outward current, that is, $10 \mathrm{msec}$ or $500 \mathrm{msec}$ after depolarizing steps to $0 \mathrm{mV}$ from a holding potential of $-100 \mathrm{mV}$. The measurement at the peak was assumed to reflect the transient component almost exclusively, be- 

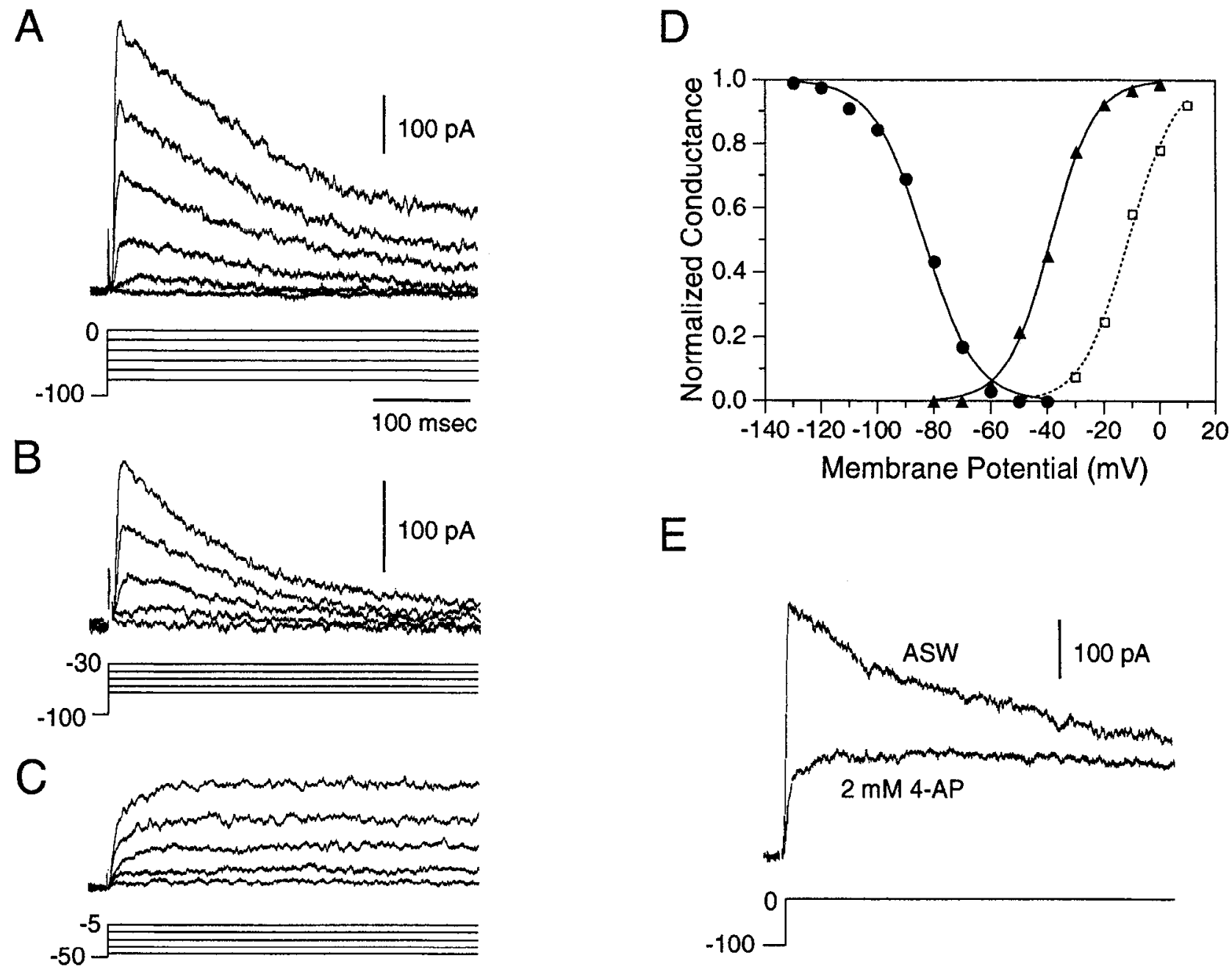

Figure 2. Voltage-dependent outward currents of ciliary-type photoreceptors in the dark. Depolarizing steps with $500 \mathrm{msec}$ duration were applied at time intervals of $10 \sec (A-C)$. $A$, Total outward currents were elicited by depolarizing steps to varying voltage $(-75 \mathrm{mV}$ to $0 \mathrm{mV}$ in $15 \mathrm{mV}$ increments) from a holding potential of $-100 \mathrm{mV} . B$, The transient $\mathrm{K}^{+}$currents were elicited by voltage steps up to $-30 \mathrm{mV}$. The cell was held at $-100 \mathrm{mV}$ and then stepped to test voltages from $-70 \mathrm{mV}$ to $-30 \mathrm{mV}$ in $10 \mathrm{mV}$ increments. $C$, The maintained $\mathrm{K}^{+}$currents were activated at more positive potentials. The holding potential was $-50 \mathrm{mV}$. Depolarizing steps to test voltages from $-45 \mathrm{mV}$ to $-5 \mathrm{mV}$ were applied in $10 \mathrm{mV}$ increments. Vertical scale of $C$ is the same as $A$. $D$, Voltage dependence of the activation and the steady-state inactivation; data from one cell. The normalized conductances are plotted as a function of prepulse voltage for the steady-state inactivation of the transient $\mathrm{K}^{+}$currents (solid circles) and as a function of depolarizing voltage for the activation of the transient $\mathrm{K}^{+}$currents (solid triangles) and for the activation the maintained $\mathrm{K}^{+}$ currents (open squares). The fitted curves are Boltzmann functions of slope $8.9, V_{12}-83$ (circles), slope $-7.7, V_{1 / 2}-39$ (triangles) and slope -7.9 , $V_{1 / 2}-11$ (squares). The methods for obtaining these curves are described in Results. $E$, Effect of 4-AP on total outward currents. Outward currents were activated by a depolarizing step to $0 \mathrm{mV}$ after holding by $2 \mathrm{sec}$ prepulse to $-100 \mathrm{mV}$, in the absence (ASW) or the presence of $2 \mathrm{~mm} 4$-AP.

cause the contamination by maintained component was estimated $<10 \%(n=4)$. The reversal potential measured $-90 \pm 4$ $\mathrm{mV}$ for the peak and $-88 \pm 6 \mathrm{mV}$ for the maintained current and was almost exactly the Nernst $\mathrm{K}^{+}$equilibrium potential ( $n$ $=4$ ). Therefore, it is clear that both the transient and the maintained components of the outward current were carried by potassium ions.

Voltage dependency of transient and maintained current is illustrated in Figure $2 D$. The activations of both transient and maintained currents were examined using the same protocols as Figure $2 A-C$. The peak conductance was calculated by dividing the peak currents at each depolarizing voltage with the driving force using the relation of Equation 1, and then normalized by fitting it to the Boltzmann function of Equation 2.

To examine the steady-state inactivation of transient current, a two-pulse voltage protocol was used. A depolarizing test pulse was applied to $-35 \mathrm{mV}$ after holding by a $500 \mathrm{msec}$ prepulse to different voltages $(-130 \mathrm{mV}$ to $-40 \mathrm{mV}$ in $10 \mathrm{mV}$ increments). The peak currents measured with different prepulse voltages were normalized by a curve fitting the Boltzmann function as described above (modified form of the Equation 2, $I / I_{\max }=$ $1 /\left\{1+\exp \left(\left(V-V_{1 / 2}\right) / k\right)\right\}$, was used $)$.

We tested the classical $\mathrm{K}^{+}$channel blockers 4-AP and TEA for the pharmacological separation of these $\mathrm{K}^{+}$currents (Thompson, 1977). The transient current was selectively blocked by 4-AP (Fig. 2E). In the presence of $2 \mathrm{~mm} \mathrm{4-AP,} \mathrm{the} \mathrm{transient}$ current was almost completely blocked $(>95 \%, n=3)$, although the maintained current was less sensitive and was depressed only partially $(\approx 20 \%, n=3)$.

TEA also has an effect on the outward $\mathrm{K}^{+}$currents, but it seems to depress both of two currents unselectively, and these currents are not blocked completely even at a high concentration 
A
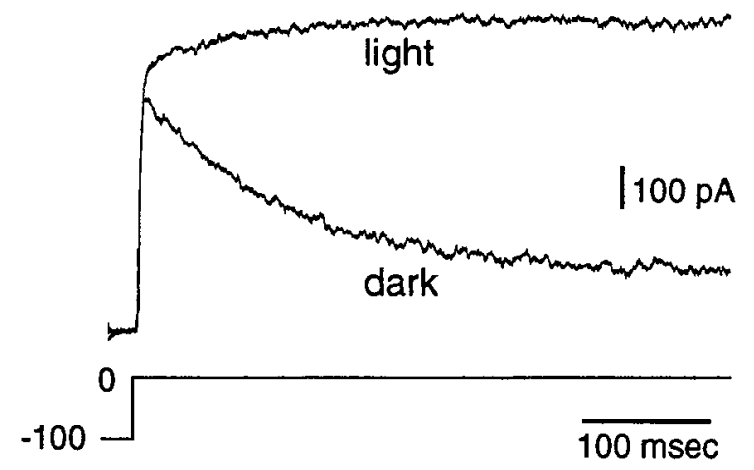

C

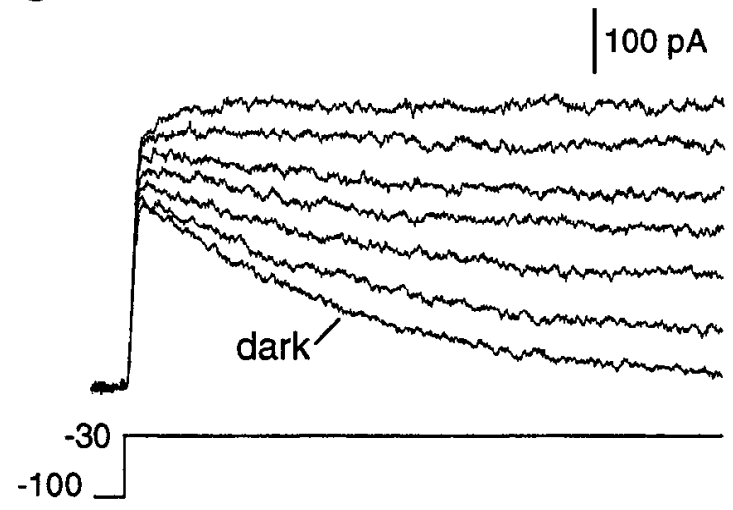

B

\section{2 mM 4-AP}
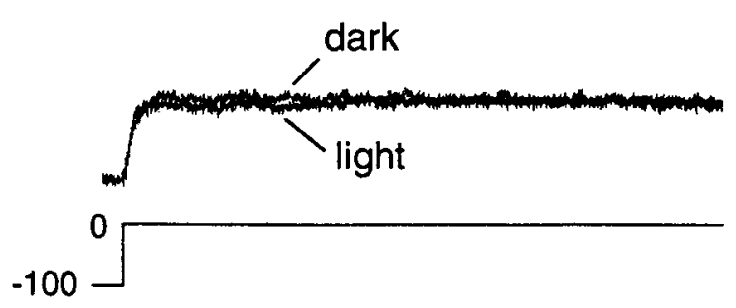

D

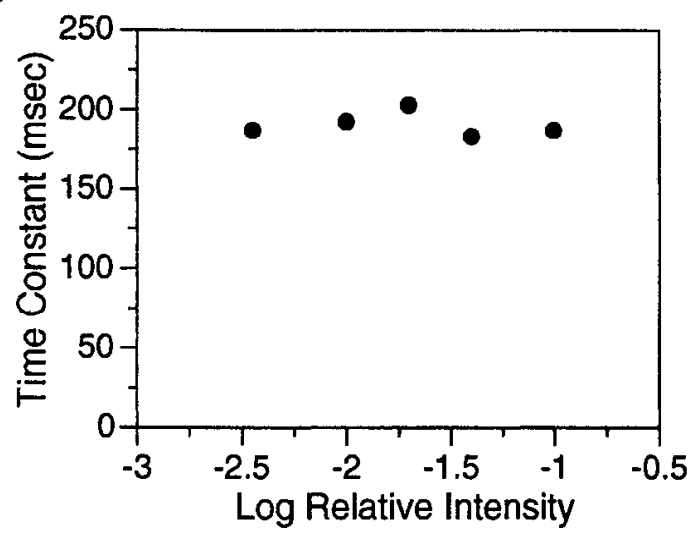

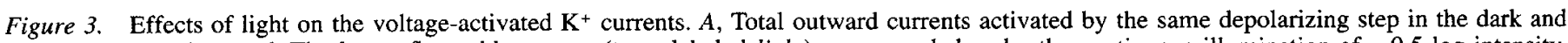

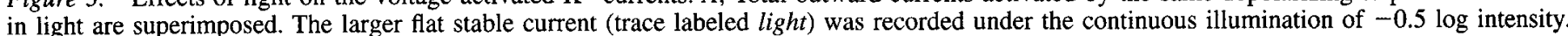

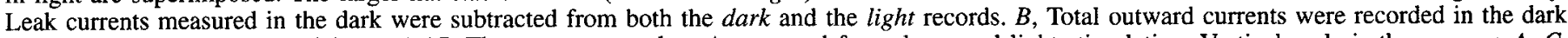

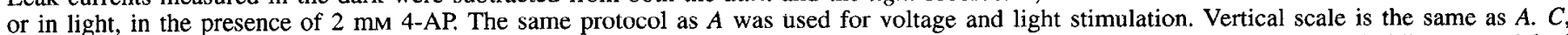

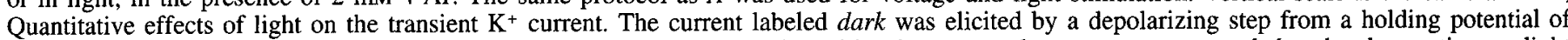

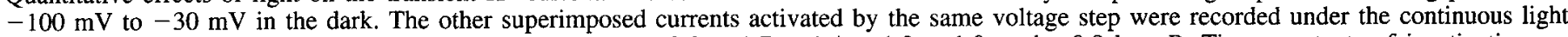

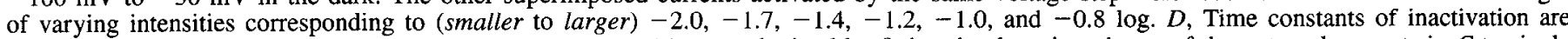

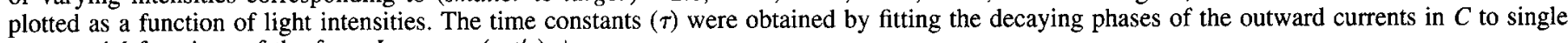
exponential functions of the form $I=a \exp (-t / \tau)+c$.

(50 mM) of TEA (data not shown). Thus, TEA was not convenient for isolating the two $\mathrm{K}^{+}$currents pharmacologically.

No current was found that showed any dependence upon external $\mathrm{Ca}^{2+}$ ions. Elevation $(20 \mathrm{mM})$ or removal $\left(0 \mathrm{Ca}^{2+}\right)$ of external $\mathrm{Ca}^{2+}$ ions had no significant effect on the macroscopic voltage-activated current (data not shown). Voltage-activated inward currents were not detected in these cells.

\section{Effects of light on the voltage-activated $K^{+}$currents}

As described above, activation of the light-activated current was clearly dependent on the holding potential (Fig. 1B,C). This result suggests the possibility that the light-activated $\mathrm{K}^{+}$channels are also voltage-sensitive. To examine this suggestion, we compared the voltage-activated currents in light and dark. A continuous light $(\log I=-0.5)$ was turned on $1.5 \mathrm{sec}$ preceding the depolarizing step to $0 \mathrm{mV}$ from a holding potential of $-100 \mathrm{mV}$. We assumed that the effect of light was constant during the recording period of $500 \mathrm{msec}$, because the light-activated currents had reached their saturated levels within $1.5 \mathrm{sec}$ after turning on a light and decayed very slowly during the following 500 msec $(1.7 \pm 0.7 \%$ of the total current, $n=7)$ if the photoreceptors were held at steady potentials (see insets of Fig. 1A,B). In all following recordings in light, light was turned on $1.5 \mathrm{sec}$ preceding the depolarizing test steps. The total currents activated in the dark and in light were superimposed in Figure $3 A$.

The outward current was activated rapidly in light. However, after it reached the peak, the current did not decay, and maintained the peak amplitude during the recording period. Thus, in light, another voltage-dependent component which canceled the appearance of inactivation was added. To measure the reversal potential of this "light-sensitive" component, the tail current was elicited by hyperpolarizing pulses following a $500 \mathrm{msec}$ prepulse to $-35 \mathrm{mV}$ at which both the transient and the maintained $\mathrm{K}^{+}$current were not activated in the dark. The reversal potential measured $-90 \pm 4 \mathrm{mV}(n=4)$ and indicated that the light-sensitive component was also carried by potassium ions. This component did not show obvious dependence upon external $\mathrm{Ca}^{2+}$ ions although a slight elevation of peak current was recognized in the $0 \mathrm{Ca}^{2+}$ solution (data not shown).

The light-sensitive component was also strongly blocked by 
4-AP. In the presence of external $2 \mathrm{~mm} 4$-AP, both the transient $\mathrm{K}^{+}$current and the light-sensitive component were blocked almost completely. The remaining current (i.e., the maintained $\mathrm{K}^{+}$ current) was nol affected by light (Fig. 3B).

To examine the quantitative effect of light, a fixed depolarizing step, from a holding potential of $-100 \mathrm{mV}$ to $-30 \mathrm{mV}$, was applied with different light intensities. In proportion as the intensity was increased, the amount of decayed current was reduced with a slight increase of the peak current (Fig. 3C). The time course of the decay in each light intensity was well fit with a single exponential function. The time constants obtained by this fitting are plotted against the intensity of light in Figure $3 D$. The time constant for decay was generally not affected by light. This indicates that light reduces the amount of decay, but does not slow it.

To decide whether light modifies the inactivation of the transient $\mathrm{K}^{+}$current or activates another class of $\mathrm{K}^{+}$channels, we compared the kinetics of the inactivation process in light with in the dark (Figs. 4, 5). The two-pulse protocols used for these experiments are illustrated in each figurc.

Figure 4 shows the effect of bright light on the steady-state inactivation of the transient $\mathrm{K}^{+}$current. Total outward currents were elicited in the dark or in light by a depolarizing test step from $-100 \mathrm{mV}$ to $0 \mathrm{mV}$ following $500 \mathrm{msec}$ conditioning pulse of varying voltage (Fig. $4 A, B$ ). The amplitudes of total outward currents were measured at $10 \mathrm{msec}$ after the test steps and plotted as a function of conditioning pulse vollage (Fig. $4 \mathrm{C}$ ). In the dark, the inactivation of the transient $\mathrm{K}^{+}$current was clearly dependent on the voltage of the conditioning pulse. However, in bright light, voltage dependence of the inactivation disappeared completely and outward currents activated equally at all examined voltages of the conditioning pulse.

To measure the progress of inactivation, the test pulse -100 $\mathrm{mV}$ to $0 \mathrm{mV}$ was applied following depolarized conditioning pulse to $-40 \mathrm{mV}$ of varying duration (Fig. $5 A-C$ ). Before each conditioning pulse, the ccll was held at $-100 \mathrm{mV}$ for $1 \mathrm{sec}$ to remove the inactivation. The longer the duration of the conditioning pulse, the smaller the amplitude of the transient $\mathrm{K}^{+}$current became in the dark. The time course of the progress of the inactivation was approximated by a single exponential function with time constant of $138 \pm 34 \mathrm{msec}(n=4)$. As shown in Figure $5, B$ and $C$, inactivation was prevented completely in bright light.

The recovery from inactivation is shown in Figure $5 D-F$. The cell was held at $-40 \mathrm{mV}$ for several seconds to inactivate the transient $\mathrm{K}^{+}$current completely, and then held at the conditioning pulse to $-100 \mathrm{mV}$ of variable duration before the test pulse to $0 \mathrm{mV}$. In the dark, the transient $\mathrm{K}^{+}$current recovered from inactivation single-exponentially by increasing the duration of the conditioning pulse (Fig. 5D,F). The time constant for recovery was $82 \pm 15 \mathrm{msec}(n=3)$. In contrast, the process of rccovery from inactivation was not detectable in bright light (Fig. $5 E, F$ ).

These results strongly indicate that light modifies the inactivation process of the transient $\mathrm{K}^{+}$current and suppresses its progress. Since we observed no other outward current affected by light, we concluded that the light-activated $\mathrm{K}^{+}$channel is the voltage-activated transient $\mathrm{K}^{+}$channel.

\section{Discussion}

In this study, we show that the light-activated $\mathrm{K}^{+}$channels in Patinopecten ciliary-type photoreceptors are also voltage acti-
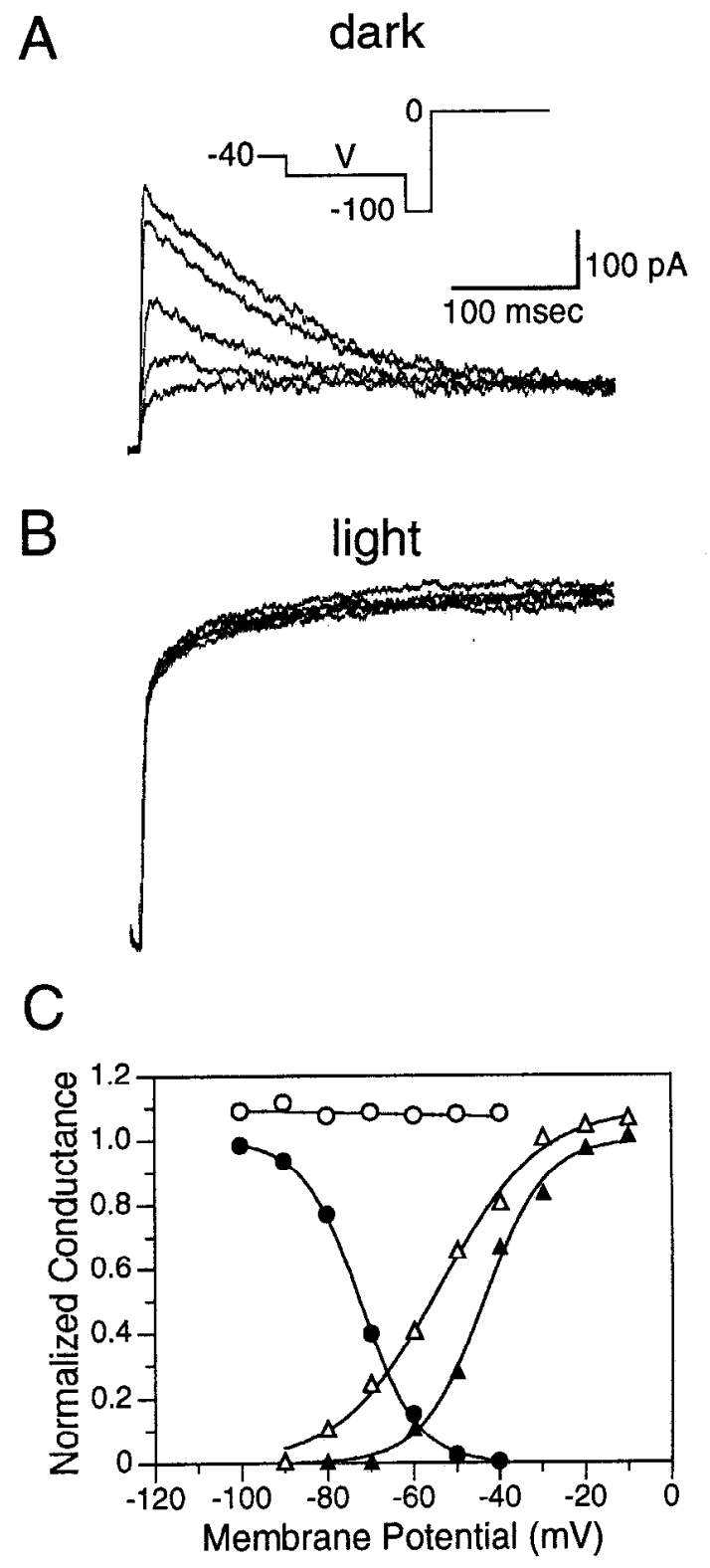

Figure 4. Effects of light on the steady-state inactivation of the transient $\mathrm{K}^{+}$currents. $A$, In the dark, total outward currents were elicited by a depolarizing test step to $0 \mathrm{mV}$ following $500 \mathrm{msec}$ conditioning pulses of varying voltage ( $V$, from -90 to $-50 \mathrm{mV}$ in $10 \mathrm{mV}$ increments). The inset shows the two-pulse protocol. Interpulse interval is 10 msec. $B$, Outward currents elicited in bright light $(\log I=-0.5)$. The voltage protocol is the same as $A$. $C$, 'The steady-state inactivation in the dark (solid circles) and in light (open circles). Data were normalized to the value of maximum amplitude in the dark after the noninactivating component in the dark was subtracted, and plotted as a function of conditioning pulse voltage. In $C$, activation of the total outward currents in the dark (solid triangles) and in light (open triangles) are also plotted as a function of test step voltage depolarized from a holding potential of $-100 \mathrm{mV}$ (method is the same as Fig. $2 B$ ). Curves fitted to data points are Boltzmann functions of slope 6.6, $V_{1 / 2}$ -73 (solid circles), slope $-7.1, V_{1 / 2}-44$ (solid triangles) and slope $-11.5, V_{1 / 2}-54$ (open triangles). The data shown in $A-C$ are from the same cell. 
A

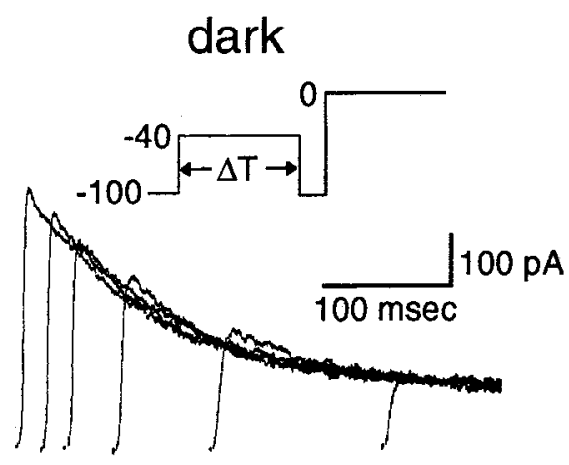

B

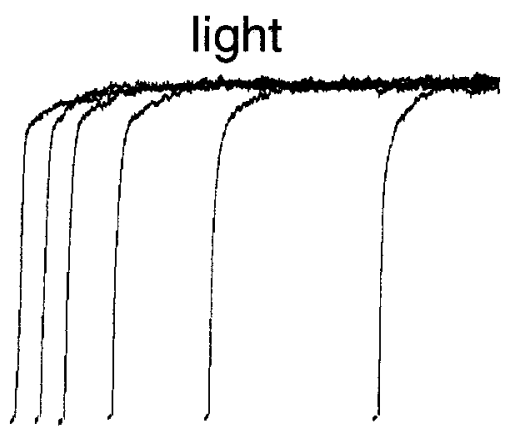

C

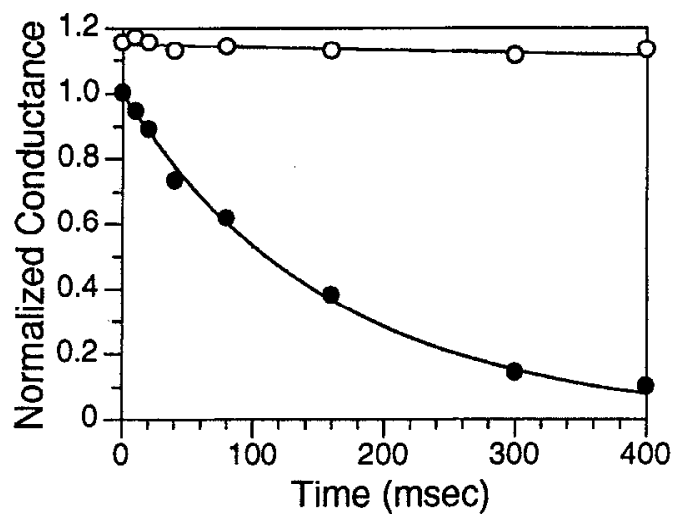

$\mathrm{D}$

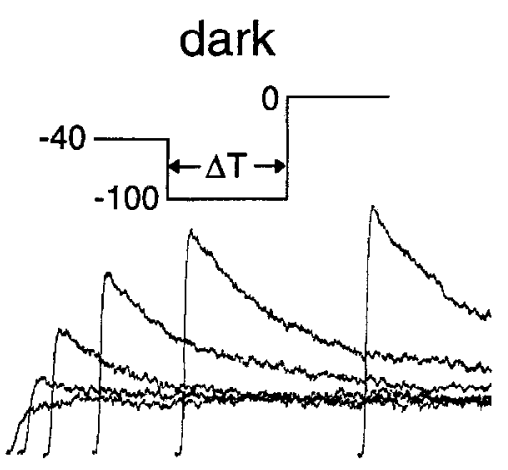

$E$

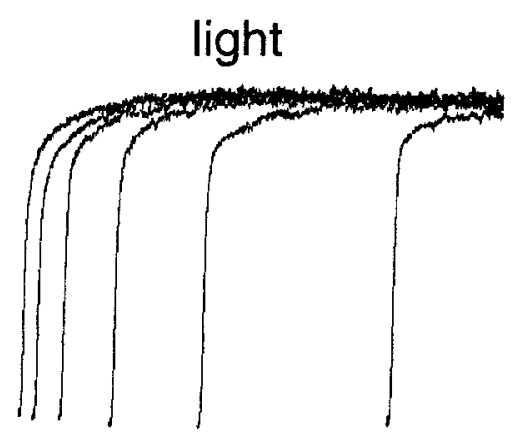

F

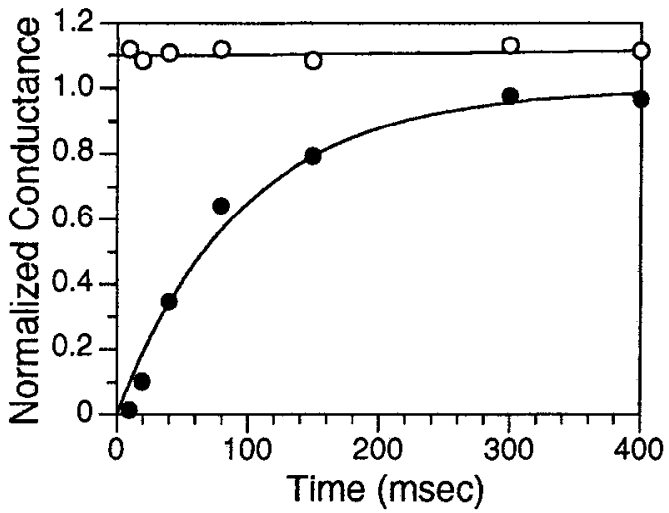

Figure 5. Effects of light on the inactivation kinetics of the transient $\mathrm{K}^{+}$currents. The progress of $(A-C)$ and the recovery from the inactivation $(D-F)$ were recorded in the dark $(A, D)$ or in light $(B, E, \log I=-0.5)$. The insets show the two-pulse protocols. The data in $A-C$ and $D-F$ are, respectively, from the same cells. $A$ and $B$, The currents were recorded with a conditioning pulse to $-40 \mathrm{mV}$ of varying duration $(\Delta t, 0,20,40$, 80,160 , and $300 \mathrm{msec}$ ). Interpulse interval is $10 \mathrm{msec}$. $C$, The time course of the progress of inactivation in the dark (solid circles) and in light (open circles) are plotted as a function of the duration of the conditioning pulse. Curve is a single exponential with time constant of 159 msec. $D$ and $E$, The currents were recorded with variable conditioning pulse duration $(\Delta t, 10,20,40,80,150$, and $300 \mathrm{msec}) . F$, The time course of the recovery in the dark (solid circles) and in light (open circles) are plotted as a function of the duration of conditioning pulse. Curve is a single exponential with time constant of $97 \mathrm{msec}$. In $C$ and $F$, data were obtained and normalized using the same method as Figure $4 C$.

vated. The light-activated $\mathrm{K}^{+}$channels produce a transient $\mathrm{K}^{+}$ current in response to a depolarizing step in the dark, and light suppresses the inactivation process of this current.

Our results strongly indicate that the light-activated $\mathrm{K}^{+}$current of the ciliary-type photoreceptor is produced by removing inactivation of $\mathrm{K}^{+}$channels.

\section{Voltage-dependent $K^{+}$channels}

Present results indicatc that there are at least two classes of voltage-dependent $\mathrm{K}^{+}$channel currents in the ciliary-type photoreceptors (Fig. 2). These currents may be usually classified as an A-current and a delayed rectifier respectively, but we did not do so because the transient $\mathrm{K}^{+}$channels are also light sensitive. Since there is no component that shows fast inactivation in bright light (Figs. 4, 5), the transient $\mathrm{K}^{+}$channels involved in the ciliary-type photoreceptors are only one type, that is, the light-activated $\mathrm{K}^{+}$channels. Thus, the ciliary-type photoreceptor seems to lack the pure A-type $\mathrm{K}^{+}$channels. However, the "darkkinetics" of the light-activated $\mathrm{K}^{+}$channels closely resembles that of molluscan A-currents (Connor and Stevens, 1971; Neher, 1971; Thompson, 1977). (1) They are transient potassium currents showing a fast inactivation in response to the depolarizing voltage steps. (2) Activation occurs at a potential near $-65 \mathrm{mV}$. (3) The voltage dependence of the steady-state inactivation is 
steep, with a midpoint near $-70 \mathrm{mV}$. (4) They are blocked selectively by millimolar 4-AP, but less sensitive to block by TEA.

The light-activated $\mathrm{K}^{+}$channels may be very close to the A-type $\mathrm{K}^{+}$channels on the molecular structure and the mechanisms of activation and inactivation.

We did not detect calcium-activated $\mathrm{K}^{+}$channels activated by voltage-dependent entering of extracellular $\mathrm{Ca}^{2+}$ ions. Similar independence of $\mathrm{K}^{+}$current from external $\mathrm{Ca}^{2+}$ ions has been also reported in other photoreceptors (Hardie, 1991a; Weckstrom et al., 1991). However, the possibility still remains that there are $\mathrm{K}^{+}$channels, including the light-activated channel, modulated by intracellular $\mathrm{Ca}^{2+}$. As described above, extracellular application of TEA was not useful for the selective blockage of the maintained $\mathrm{K}^{+}$current. Although we did not try the intracellular perfusion of TEA, it may be more effective for the blockage of maintained $\mathrm{K}^{+}$currents in invertebrate photoreceptors (Lisman et al., 1982).

The maintained $\mathrm{K}^{+}$channels may be related to the stability of the resting potential in the dark. It is known that, in the ciliary-type photoreceptors, relatively high permeability of sodium ions through the membrane tends to lower the membrane potential (Gorman and McReynolds, 1978). As the maintained $\mathrm{K}^{+}$ current is activated at low membrane potential (Fig. 2), the noninactivating component of it yields an outward rectification across the potential of about $-40 \mathrm{mV}$, and prevents the membrane from depolarizing more. As a result, the membrane potential is stabilized at the resting potential of -30 to $-40 \mathrm{mV}$.

\section{Effects of light}

Light brings a dramatic but simple change on the kinetics of the light-activated $\mathrm{K}^{+}$channels. Since the outward $\mathrm{K}^{+}$current in light also rises time-dependently from the same current level as in the dark (Fig. 3B), the effect of light seems to be restricted to the mechanism of inactivation.

Various methods are known presently to remove inactivation from, or add inactivation to the voltage-gated channels by means of chemical reagents (Gonoi and Hille, 1987; Matteson and Carmeliet, 1988; Oxford and Wagoner, 1989), synthetic peptide (Rettig et al., 1994), mutants (Zagotta et al., 1990), or chimeric channels (Zhang et al., 1994).

The "light-kinetics" of the light-activated $\mathrm{K}^{+}$channels shows the same properties as the noninactivating channels in these experiments. (1) They show a flat stable current activated by depolarizing steps. (2) The activated current initially rises at the same rate as the current of inactivating channels. (3) The peak current increases as compared with the peak of the inactivating current.

Furthermore, the effect of light on the outward $\mathrm{K}^{+}$current could be easily simulated using the Hodgkin-Huxley model (Hodgkin and Huxley, 1952) on the supposition that light simply reduces the number of inactivating channels (Shimatani and Katagiri, unpublished data), except for the hyperpolarizing shift of the activation curve in light (Fig. 4C). Gonoi and Hille (1987) showed that with papain treated neuroblastoma cells, the removal of inactivation unmasked the "slow activation" kinetics of $I_{\mathrm{Na}}$ and unmasked the "true" activation curve shifted in the hyperpolarizing direction, and that these results were well explained by the Armstrong-Bezanilla-Aldrich-Corey-Stevens (ABACS) model (Hill, 1992). The kinetics of the light activated $\mathrm{K}^{+}$channels may be explained by the ABACS model.

In Limulus ventral photoreceptors, the maintained voltage-dependent $\mathrm{K}^{+}$current showed a slight, long-lasting decrease during light adaptation (Chinn and Lisman, 1984). In the ciliary-type photoreceptors, the transient $\mathrm{K}^{+}$current quickly regains its darkkinetics after light is turned off. Prolonged illuminations (up to $30 \mathrm{scc}$ ) or repetitive light stimuli have no long-lasting effect on the dark-kinetics of the transient $\mathrm{K}^{+}$current or on the maintained $\mathrm{K}^{+}$current.

\section{The light-activated $\mathrm{K}^{+}$current}

Since the light-activated $\mathrm{K}^{+}$channels are inactivated at the resting potentials of the photoreceptors, light should remove inactivation to generate the hyperpolarizing receptor potential or the light-activated outward current. This consequence corresponds to the results that indicate the generation of the light-activated current is dependent on the state of inactivation of the lightactivated $\mathrm{K}^{+}$channels in the dark. As shown in Figure $1 B$, the light-activated current does not reverse at holding potentials more negative than Nernst potential for $\mathrm{K}^{+}$. At voltages more negative than $-80 \mathrm{mV}$, the light-activated $\mathrm{K}^{+}$channels are closed but not inactivated (Fig. $2 D$ ). Light does not activate such channels if it removes inactivation but does not open the channels. Consequently, the voltage dependency of the light-activated membrane conductance change (Fig. 1C) is identical with the steady-state activation of the light-activated $\mathrm{K}^{+}$channels in light (Fig. 4C).

Recently, Gomez and Nasi (1994a) reported that the lightinduced currents of ciliary-type photoreceptors from Pecten and Lima show "outward rectification" in ASW, and that the lightinduced membrane conductance change decreases as the membrane is hyperpolarized. The light-activated channels of these species may be also activated by voltage in the dark.

In Patinopecten the light-activated $\mathrm{K}^{+}$channels should possess both second messenger and voltage-gated mechanisms. Interestingly, the amino acid sequences of cyclic nucleotide-gated channels from vertebrate olfactory and retinal receptors show significant homology with voltage-gated $\mathrm{K}^{+}$channels (Jan and Jan, 1990; Heginbotham et al., 1992).

Recently, Kramer at al. (1994) showed that the Shaker K+ channel inactivation peptide ("ball peptide") blocked the cyclic nucleotide-gated and voltage-gated channels in their open state and prevented channel closure. They suggested that the gating of cyclic nucleotide-gated channels and voltage-gated channels involves similar conformational changes in channel structure.

As the cyclic nucleotide binding site is contained in the C-terminal, it has been suggested that the C-terminal may interact with the cytoplasmic face of the channel and maintain it in a closed or inactive state until the interaction is blocked by the binding of cyclic nucleotide (Goulding et al., 1992). C-terminal is known to cause a slow inactivation (C-type inactivation) to Shaker $\mathrm{K}^{+}$channels after removal of the $\mathrm{N}$-terminal ball domain (Hoshi et al., 1991). These findings suggest that C-terminal may possibly act as both a second messenger-dependent gate and voltage dependent inactivation gate.

On the other hand, many examples are known presently in which the voltage-gated $\mathrm{K}^{+}$channels are modulated by intracellular environments (Rudy, 1988), such as $\mathrm{Ca}^{2+}$ (Chinn and Lisman, 1984), $\mathrm{O}_{2}$ tension (Ganfornina and Lopez-Barneo, 1991), cysteine oxidation (Ruppersberg et al., 1991), cyclic nucleotide (Strong and Kaczmarek 1986; O'Grady et al., 1991), or protein kinase phosphorylation (Drain ct al., 1994). Recently, $\beta$-subunit of voltage-gated ion channels of rat brain have been reported to confer a rapid A-type inactivation on noninactivating $\mathrm{K}^{+}$channels (Rettig et al., 1994). Since $\beta$-subunits of voltage- 
gated $\mathrm{K}^{+}$channels can be phosphorylated in the intact $\mathrm{K}^{+}$channels (Scott et al., 1994), the second messenger-activated protein kinases may regulate channel function by phosphorylating $\beta$-subunits (Isom ct al., 1994).

Although the gating mechanisms of second messenger-gated channels and molluscan voltage-gated $\mathrm{K}^{+}$channels are not clear yet, our results suggest that the invertebrate ciliary-type photoreceptors modify the inactivation mechanisms of voltage-gated $\mathrm{K}^{+}$channels to generate the hyperpolarizing receptor potential.

\section{References}

Barber VC, Evans EM, Land MF (1967) The fine structure of the eye of the mollusc Pecten maximus. Z Zellforsch 76:295-312.

Brown JE, Blinks JR (1974) Changes in intracellular free calcium concentration during illumination of invertebrate photoreceptors. J Gen Physiol 103:409-427.

Chinn K, Lisman J (1984) Calcium mediates the light-induced decrease in maintained $\mathrm{K}^{+}$current in Limulus ventral photoreceptors. J Gen Physiol 84:447-462.

Clark AW, Millecchia R, Mauro A (1969) The ventral photoreceptor cells of Limulus. I. The microanatomy. J Gen Physiol 54:289-309.

Connor JA, Stevens CF (1971) Voltage clamp studies of a transient outward membrane current in gastropod neural somata. J Physiol (Lond) 213:21-30.

Drain P, Dubin AE, Aldrich RW (1994) Regulation of Shaker $\mathrm{K}^{+}$channel inactivation gating by the cAMP-dependent protein kinase. Neuron 12:1097-1109.

Fenwick EM, Marty A, Neher E (1982) A patch-clamp study of bovine chromaffin cells and their sensitivity to acetylcholine. J Physiol (Lond) 331:577-597.

Fesenko EE, Kolesnikov SS, Lyubarsky AL (1985) Induction by cyclic GMP of cationic conductance in plasma membrane of retinal rod outer segment. Nature 313:310-313.

Ganfornina MD, Lopez-Barneo J (1991) Single $\mathrm{K}^{+}$channels in membrane patches of arterial chemoreceptor cells are modulated by $\mathrm{O}_{2}$ tension. Proc Natl Acad Sci USA 88:2927-2930.

Gomez M, Nasi E (1994a) The light-sensitive conductance of hyperpolarizing invertebrate photoreceptors: a patch-clamp study. J Gen Physiol 103:939-956.

Gomez M, Nasi E (1994b) Blockage of the light-sensitive conductance in hyperpolarizing photoreceptors of the scallop. J Gen Physiol 104: 487-505.

Gonoi T, Hille B (1987) Gating of Na channels. Inactivation modifiers discriminate among models. J Gen Physiol 89:253-274.

Gorman ALF, McReynolds JS (1969) Hyperpolarizing and depolarizing receptor potentials in the scallop eye. Science 165:309-310.

Gorman ALF, McReynolds JS (1974) Control of membrane $\mathrm{K}^{+}$permeability in a hyperpolarizing photoreceptor: similar effect of light and metabolic inhibitors. Science 185:620-621.

Gorman ALF, McReynolds JS (1978) Ionic effects on the membrane potential of hyperpolarizing photoreceptors in scallop retina. J Physiol (Lond) 275:345-355.

Goulding EH, Ngai J, Kramer RH, Colicos S, Axel R, Siegelbaum SA, Chess A (1992) Molecular cloning and single-channel properties of the cyclic nucleotide-gated channel from catfish olfactory neurons. Neuron 8:45-58.

Hamill OP, Marty A, Neher E, Sakmann B, Sigworth FJ (1981) InIproved patch-clamp techniques for high-resolution current recording from cells and cell-free membrane patches. Pfluegers Arch 391:85100.

Hardie RC (1991a) Voltage-sensitive potassium channels in Drosophila photoreceptors. J Neurosci 11:3079-3095.

Hardie RC (1991b) Whole-cell recordings of the light induced current in dissociated Drosophila photoreceptors: evidence for feedback by calcium permeating the light-sensitive channels. Proc R Soc Lond [Biol] 245:203-210

Heginbotham L, Abramson T, MacKinnon R (1992) A functional con- nection between the pores of distantly related ion channels as revealed by mutant $\mathrm{K}^{+}$channels. Science $258: 1152-1155$.

Hille B (1992) Ionic channels of excitable membranes, second edition. Sunderland, MA: Sinauer.

I Iodgkin AL, Huxley AF (1952) A quantitative description of Inembrane current and its application to conduction and excitation in nerve. J Physiol (Lond) 117:500-544.

Hoshi T, Zagotta WN, Aldrich RW (1991) Two types of inactivation in Shaker $\mathrm{K}^{+}$channels: effects of alterations in the carboxy-terminal region. Neuron 7:547-556.

Isom LL, DeJongh KS, Catterall WA (1994) Auxiliary subunits of voltage-gated ion channels. Neuron 12:1183-1194.

Jan LY, Jan YN (1990) A superfamily of ion channels. Nature 345: 672.

Katagiri Y, Katagiri N, Fujimoto K (1985) Morphological and electrophysiological studies of a multiple photoreceptive system in a marine gastropod, Onchidium. Neurosci Res Suppl 2:1-15.

Kramer RH, Goulding EH, Siegelbaum SA (1994) Potassium channel inactivation peptide blocks cyclic nucleotide-gated channels by binding to the conserved pore domain. Neuron 12:655-662.

Lisman JE, Fain GL, O'Day PM (1982) Voltage-dependent conductances in Limulus ventral photoreceptors. J Gen Physiol 79:187-209.

Matteson DR, Carmeliet P (1988) Modification of $\mathrm{K}$ channel inactivation by papain and N-bromoacetamide. Biophys $\mathrm{J} 53: 641-645$.

McRcynolds JS (1976) Hyperpolarizing photoreceptors in invertebrates. In: Neural principles in vision (Zettler F, Weiler R, eds). Berlin: Springer.

McReynolds JS, Gorman ALF (1970a) Photoreceptor potentials of opposite polarity in the eye of the scallop, Pecten irradians. J Gen Physiol 56:376-391.

McReynolds JS, Gorman ALF (1970b) Membrane conductances and spectral sensitivities of Pecten photoreceptors. J Gen Physiol 56:392406

Millecchia R, Mauro A (1969) The ventral photoreceptor cells of $\mathrm{Li}$ mulus. II. The basic photoresponse. J Gen Physiol 54:310-330.

Mpitsos GJ (1973) Physiology of vision in the mollusk Lima scabra. J Neurophysiol 36:371-383.

Neher E (1971) Two fast transient current components during voltage clamp on snail neurons. J Gen Physiol 58:36-53.

O'Grady SM, Cooper KE, Rae JL (1991) Cyclic GMP regulation of a voltage-activated $\mathrm{K}$ channel in dissociated enterocytes. J Membr Biol 124:159-167.

Oxford GS, Wagoner PK (1989) The inactivating $\mathrm{K}^{+}$current in GH3 pituitary cells and its modification by chemical reagents. J Physiol (Lond) 410:587-612.

Rettig J, Heinemann SH, Wunder F, Lorra C, Parcej DN, Dolly JO, Pongs O (1994) Inactivation properties of voltage-gated $\mathrm{K}^{+}$channels altered by presence of $\beta$-subunit. Nature 369:289-294.

Rudy B (1988) Diversity and ubiquity of potassium channels. Neuroscience 25:729-749.

Ruppersberg JP, Stocker M, Pongs O, Heinemann SH, Frank R, Koenen M (1991) Regulation of fast inactivation of cloned mammalian Ik(A) channels by cysteine oxidation. Nature 352:711-714.

Scott VES, Rettig J, Parcej DN, Keen JN, Findlay JBC, Pongs O, Dolly JO (1994) Primary structure of a $\beta$ subunit of $\alpha$-dendrotoxin-sensitive $\mathrm{K}^{+}$channels from bovine brain. Proc Natl Acad Sci USA 91: 1637-1641.

Strong JA, Kaczmarek LK (1986) Multiple components of delayed potassium current in peptidergic neurons of Aplysia: modulation by an activator of adenylate cyclase. J Neurosci 6:814-822.

Thompson SH (1977) Three pharmacologically distinct potassium channels in molluscan neurones. J Physiol (Lond) 265:465-488.

Weckstrom M, Hardie RC, Laughlin SB (1991) Voltage-activated potassium channels in blowfly photoreceptors and their role in light adaptation. J Physiol (Lond) 440:635-657.

Wilkens LA (1984) Ultraviolet sensitivity in hyperpolarizing photoreceptors of the giant clam Tridacna. Nature 309:446-448.

Zagotta WN, Hoshi T, Aldrich RW (1990) Restoration of inactivation in mutants of Shaker potassium channels by a peptide derived from ShB. Science 250:568-571.

Zhang J, Ellinor PT, Aldrich RW, Tsien RW (1994) Molecular determinants of voltage-dependent inactivation in calcium channels. $\mathrm{Na}$ ture $372: 97-100$. 